\title{
First Same-Sex Partner and the Internet
}

\author{
Dirk Franssens $\cdot$ Harm J. Hospers • \\ Gerjo Kok
}

Published online: 19 March 2010

(C) The Author(s) 2010. This article is published with open access at Springerlink.com

\begin{abstract}
The present study examined the first episode of anal intercourse of young gay and bisexual men (YGBM) who were in the midst of their coming-out. Cross-sectional data regarding the first episode of anal intercourse were extracted from Outcomes, a longitudinal study on comingout and sexual behavior of YGBM in the Netherlands. Overall, $45 \%$ of respondents reported unprotected anal intercourse (UAI) with their first same-sex partner. Rates of UAI did not significantly differ between meeting place (offline vs. online) and partner status (steady, regular or casual).
\end{abstract}

Keywords Internet $\cdot$ MSM $\cdot$ Sexual behavior ·

Young men $\cdot$ HIV prevention

\section{Introduction}

There is ample evidence that the Internet is a popular meeting place for gay and bisexual men (e.g. [1-3). Because of its anonymity the Internet may be especially appealing for young gay and bisexual men (YGBM) in their coming-out (i.e. the process of identity formation and identity integration $[4,5])$. It provides YGBM with a relative safe environment for experimenting with meeting and subsequently having sex with other gay and bisexual men $[1,6]$. Two recent studies showed that an increasing

D. Franssens · H. J. Hospers · G. Kok

Department of Work and Social Psychology, Faculty of

Psychology, Maastricht University, Maastricht, The Netherlands

H. J. Hospers $(\varangle)$

University College Maastricht, Maastricht University, PO Box 616, 6200 MD Maastricht, The Netherlands

e-mail: h.hospers@maastrichtuniversity.nl number of YGBM nowadays meet their first same-sex partner online [1, 7].

The issue whether seeking and meeting same-sex partners online facilitates high risk sexual behaviors is still unresolved. Whereas some studies found evidence that for YGBM seeking same-sex partners online results in increased risk for contracting STIs and HIV through a mechanism of more sexual risk behavior (e.g. [2]), other studies found no difference in sexual risk behavior between meeting same-sex partners online versus offline (e.g. $[8,9])$.

Considering the Internet's popularity, the question arises whether meeting the first same-sex partner online is associated with more unprotected anal intercourse (UAI). The aim of this study is to examine where YGBM who are in the midst of their coming-out, meet their first same-sex partner and whether condoms are used during the first episode of anal sex.

\section{Method}

The Outcomes study is an online cohort study on comingout and sexual behavior. Between early 2007 and late 2009 respondents completed six biannual questionnaires. The study was approved by the local ethics committee. The methods of the Outcomes study have been described in detail elsewhere [10].

Cohort participants consisted of 185 YGBM (mean age: 18.8; $\mathrm{SD}=2.3$; median: 18 , range 16-26) who were recruited both offline $(45.9 \%)$ and online $(54.1 \%)$. The eligibility criteria were: being between 16 and 25 years of age, being sexually attracted to men, and first disclosure of sexual attraction in the year prior to the first survey. Offline recruitment took place at various gay venues frequented by 
YGBM and by placing advertisements promoting the survey website in gay-related media aimed at YGBM. Online recruitment consisted of placing banners with a link to the survey website on various gay news sites frequented by YGBM.

The online questionnaire contained the following measures: demographics, sexual history (e.g., meeting place of first same-sex partner, first episode of anal intercourse and condom use during first episode) and recent sexual behavior. The online questionnaire also included other measures which will be presented elsewhere.

For the current study the following measures are used: meeting place of the first same-sex partner where anal intercourse was involved (i.e. at school, on the Internet, via friends, in gay bars, in non-gay bars, at YGBM related discussion groups, at sports club, at YGBM organizations, or elsewhere; dichotomized into offline vs. online), and condom use with first same-sex partner (yes; no). The questions pertaining to the first same-sex partner were asked during waves three and four of the Outcomes study and only to respondents who had experience with anal intercourse. In sum, the reported analyses are based on cross-sectional data from respondents who completed all four waves of Outcomes $(N=141)$, while the analyses pertaining the first episode of anal intercourse were based on respondents who reported experience with anal intercourse $(N=116)$. Chi-square tests were used to detect significant differences in UAI with first same-sex partner and meeting place (offline vs. online) and partner type (steady, regular, casual). In the present study a steady partner was defined as someone with whom respondents have a serious romantic relationship, a regular partner as someone with whom respondents regularly have sex, but without being involved in a serious romantic relationship, and a casual partner as someone with whom respondents never had sex before.

\section{Results}

Of the 141 respondents who completed all four questionnaires, $82 \%(N=116)$ reported experience with anal intercourse. The respondents who had experience with anal intercourse were very active online; only two respondents never visited gay sites on the Internet. Of the respondents who did visit gay sites, $52 \%$ visited gay sites daily, $22 \%$ between 2 and 5 times a week, and $26 \%$ once a week or less. Due to a tailoring error in the online questionnaire, 21 respondents did not receive all the questions pertaining to the first episode of anal intercourse. Therefore, only for 95 respondents complete data on the first episode of anal sex are available. No significant difference was observed between respondents for whom complete and non-complete data are available with respect to demographics and other sexual behavior variables (i.e. number of lifetime same-sex partners and recent sexual behavior and condom use; all $P$ 's $>.05)$. Therefore, the missing data are assumed to be missing at random. Of the 95 respondents for whom complete data were available and who had already engaged in anal intercourse, $45 \%$ reported UAI with their first samesex partner. Almost half of these respondents met their first same-sex partner online (47\%), 15\% through friends, $12 \%$ at school, $12 \%$ in a gay bar, $2 \%$ through sports, $1 \%$ in a non-gay bar, and $12 \%$ elsewhere (e.g. theatre, neighborhood, fashion show, etc.). There was no significant difference in UAI with the first same-sex partner when met offline $(52 \%)$ versus online $\left(38 \% ; \chi^{2}=1.9 ; P>.05\right.$; see Table 1).

Of the $45 \%$ of respondents who indicated that their first episode of anal intercourse was with a steady partner, $37 \%$ reported UAI. Of the $28 \%$ of respondents who indicated the first episode was with a regular partner, 56\% reported UAI. Finally, 26\% of the respondents had the first episode of anal intercourse with a casual partner, of whom $48 \%$ reported UAI. No significant differences in rates of UAI per partner type were observed $\left(\chi^{2}=2.36 ; P>.05\right.$; see Table 1).

\section{Discussion}

First, it should be noted that the Outcomes study has a limited sample size, which limits generalisability. Moreover, the study sample consists of YGBM who are in the midst of their coming-out. Finally, in contrast to other samples (e.g. [2,7]), our sample was both recruited offline and online. Therefore, our results should be interpreted with caution.

The main aim of this study was to examine where YGBM meet their first same-sex partner and whether meeting place was associated with sexual risk behavior

Table 1 Meeting place and partner status of the first same-sex partner where anal intercourse was involved and rate of UAI $(N=95)$

\begin{tabular}{lrr}
\hline & Percentage $(N)$ & $\%$ UAI \\
\hline Meeting place & \\
Online & $47 \%(N=45)$ & $38 \%$ \\
Offline & $53 \%(N=50)$ & $52 \% *$ \\
Partner status & \\
Steady & $45 \%(N=43)$ & $37 \%$ \\
Regular & $28 \%(N=27)$ & $56 \%$ \\
Casual & $26 \%(N=25)$ & $48 \% * *$ \\
$* \chi^{2}=1.9, P>.05 ; * * \chi^{2}=2.6, P>.05$ &
\end{tabular}


with a first same-sex partner where anal intercourse was involved. First of all, the results confirm previous observations that many YGBM are active on the Internet and that many-but not all-meet their first same-sex partner online [1-3, 7]. Moreover, almost half of the respondents did not use a condom during their first episode of anal intercourse. Third, although partner status (i.e. steady partner) is considered to be an important risk factor for HIV-infection (e.g. [11]), partner status of the first samesex partner was not associated with UAI during the first episode of anal intercourse. However, it is possible that levels of UAI increase with relationship duration [12]. Finally, in contrast to other studies (e.g. [2, 13]), no significant difference in sexual risk behavior between online and offline first same-sex partners was observed. However, much of the literature on the role of the Internet on sexual risk behavior focuses on "meeting online for sex". This raises the question whether YGBM were intentionally meeting other YGBM online for sex when they met the first same-sex partner (i.e. high risk) or just for socializing (i.e. low risk). Future studies should determine whether the context of meeting first same-sex partners online influences the decision to engage in UAI with the first same-sex partner. Furthermore, it should be noted that not engaging in anal intercourse with the first same-sex partner may have been an HIV preventive strategy for some respondents. Future studies should determine the extent to which YGBM refrain from engaging in anal intercourse with their first same-sex partner as an HIV preventive strategy.

In conclusion, the finding that a considerable proportion of YGBM engaged in UAI with first same-sex partner calls for specific HIV-prevention activities encouraging YGBM to use condoms during the first episode of anal intercourse. Furthermore, although meeting the first same-sex partner online was not associated with more risk behavior, the finding that many YGBM are active online-even in the midst of their coming-out-suggests that these HIV-prevention activities should also be delivered online.

Acknowledgment This study was financially supported by AIDS Fonds, The Netherlands. Project 2005050.
Open Access This article is distributed under the terms of the Creative Commons Attribution Noncommercial License which permits any noncommercial use, distribution, and reproduction in any medium, provided the original author(s) and source are credited.

\section{References}

1. Bolding G, Davis M, Hart G, Sherr L, Elford J. Where young MSM meet their first sexual partner: the role of the Internet. AIDS Behav. 2007;11(4):522-6.

2. McFarlane M, Bull SS, Rietmeijer CA. Young adults on the internet: risk behaviors for sexually transmitted diseases and HIV. J Adolesc Health. 2002;31(1):11-6.

3. McFarlane M, Bull SS, Reitmeijer CA. The Internet as a newly emerging risk environment for sexually transmitted diseases. JAMA. 2000;284(4):443-6.

4. Cass VC. Homosexual identity formation: testing a theoretical model. J Sex Res. 1984;22:143-67.

5. Maguen S, Floyd FJ, Bakeman R, Armistead L. Developmental milestones and disclosure of sexual orientation among gay, lesbian, and bisexual youths. J Appl Dev Psychol. 2002;23(2):21933.

6. Garofalo R, Herrick A, Mustanski BS, Donenberg GR. Tip of the iceberg: Young men who have sex with men, the Internet, and HIV risk. Am J Public Health. 2007;97(6):1113-7.

7. Balthasar H, Jeannin A, Dubois-Arber F. First anal intercourse and condom use among men who have sex with men in Switzerland. Arch Sex Behav. 2009;38(6):1000-8.

8. Horvath KJ, Rosser S, Remafedi G. Sexual risk taking among young internet-using men who have sex with men. Am J Public Health. 2008;98(6):1059-67.

9. Hospers HJ, Kok G, Harterink P, de Zwart O. A new meeting place: chatting on the internet, e-dating and sexual risk behaviour among Dutch men who have sex with men. AIDS. 2005;19:1097101.

10. Franssens D, Hospers HJ, Kok G. Social cognitive determinants of condom use in a cohort of young gay and bisexual men. AIDS Care. 2009;21:1471-9.

11. Davidovich U, de Wit J, Stroebe W. Assessing sexual risk behaviour of young gay men in primary relationships: the incorporation of negotiated safety and negotiated safety compliance. AIDS. 2000;14:701-6.

12. Hospers HJ. Homosexual men and the HIV epidemic. Understanding and changing risk behavior. Maastricht: Maastricht University; 1999.

13. Elford J, Bolding G, Sherr L. Seeking sex on the internet and sexual risk behaviour among gay men using London gyms. AIDS. 2001;15:1409-15. 